\title{
Dermal and Ophthalmic Findings in Pseudohypoaldosteronism
}

\author{
Sabriye Korkut1, Emir Gökalp2, Ahmet Özdemir1, Selim Kurtoğlu3, Şafak Demirtaş2, \\ Ülkü Gül3, Osman Baştuğ 1 \\ ${ }^{1}$ Erciyes University Faculty of Medicine, Department of Neonatology, Kayseri, Turkey \\ 2 Erciyes University Faculty of Medicine, Department of Pediatrics, Kayseri, Turkey \\ ${ }^{3}$ Erciyes University Faculty of Medicine, Department of Pediatric Endocrinology, Kayseri, Turkey
}

\begin{abstract}
Pseudohypoaldosteronism (PHA) is defined as a state of resistance to aldosterone, a hormone crucial for electrolyte equilibrium. The genetically transmitted type of PHA is primary hypoaldosteronism. Secondary hypoaldosteronism develops as a result of hydronephrosis or hydroureter. PHA patients suffer from severe hyponatremia and a severe clinical condition due to severe loss of salt can be encountered in the neonatal period. Dermal findings in the form of miliaria rubra can also develop in these patients. With the loss of salt, abnormal accumulation of sebum in the eye due to a defect in the sodium channels can also occur. In this paper, a case of PHA in a newborn showing typical dermatological and ophthalmological findings is presented. Key words: Pseudohypoaldosteronism, newborn, skin, dermal, ophthalmic, eye
\end{abstract}

Conflict of interest: None declared Received: 17.11.2014

\section{Introduction}

Aldosterone is a hormone which plays an important role in electrolyte balance in the human body. A state of resistance to aldosterone is known as pseudohypoaldosteronism (PHA). PHA types with genetic transmission are called primary PHA, while those resulting from hydronephrosis and other urogenital problems are called secondary PHA $(1,2,3)$. Although a state of salt depletion characterized by hyponatremia, hyperpotassemia and metabolic acidosis may occur due to other causes, detection of a high serum aldosterone along with these findings usually leads to a diagnosis of PHA $(1,4,5,6)$. Primary PHA type 1 is the most frequently encountered form. Inheritance of type 1 PHA cases can be autosomal recessive or autosomal dominant (6). The autosomal dominant form, with aldosterone receptor resistance restricted to the kidneys only and generally resolving in early childhood, is clinically milder. The problems encountered in cases with autosomal recessive forms of PHA stem from the mutations in the genes related with the subunit of epithelium sodium channels. Known as systemic PHA 1, this form involves, in addition to the kidneys, the sweat glands, the distal colon, the lungs, the reproductive organs and the salivary glands and its clinical figure follows a more acute course (7). These patients may present in the neonatal period in a severe state due to grave loss of salt and cardiac arrhythmia (8). They may also present with respiratory distress, pulmonary infection and cystic fibrosis-like symptoms (9). Dermal and ophthalmic findings may be present in PHA cases and these findings may be of great importance for early diagnosis $(10,11,12,13,14)$. During the attacks of salt depletion, miliaria rubra may be observed in the skin resulting from the 
accumulation and excretion of sodium in sweat glands $(10,11)$. Abnormal accumulation of sebum in the eyes is quite typical and may also occur in secondary infections $(12,13,14)$. In this paper, we present a patient who was hospitalized with miliaria and specific ophthalmic findings in the neonatal period and a review of the relevant literature.

\section{Case Report}

Our patient was a female baby referred to our clinic on postpartum $7^{\text {th }}$ day with a skin rash and lacrimation. The infant was reported to be delivered by caesarean section at a gestational age of 39 weeks. Weight at birth was $3050 \mathrm{~g}$. The baby had been given to her mother immediately after birth, she had been discharged on postnatal day 2 , only to be returned the following day with erythema and lacrimation. It was also learned that, despite a treatment consisting of an ointment for her skin and application of an antibiotic containing eye drop, her condition had not been resolved. The mother's history revealed that throughout her pregnancy, which had a normal course, she had attended all her follow-up visits, that she and her husband were cousins and their first child had died of an infection on the $10^{\text {th }}$ postpartum day.

At admission, the infant's body weight was $2740 \mathrm{~g}$ (10th-25th percentiles). Her length was $52 \mathrm{~cm}$ (50th-75th percentiles) and her head circumference was $35 \mathrm{~cm}$ (50th percentile). The general condition of the patient appeared to be good and she was active. Miliaria rubra were noted on her face, her arms and her chest (Figure 1). Presence of salt crystals could be detected at the base of the follicles of the face (Figure 2). There was a white opaque discharge at the bottom of the eyelashes and macerations around the eye were noted (Figure 3). The remaining systemic examination findings were normal. Laboratory assessment revealed a hemoglobin level of 19.5 $\mathrm{g} / \mathrm{dL}$, WBC $18870 / \mathrm{mm}^{3}$, a thrombocyte count of $412000 /$ $\mathrm{mm}^{3}$, a hematocrit level of $59 \%$. C-reactive protein level was $3.44 \mathrm{mg} / \mathrm{L}$, blood glucose $82 \mathrm{mg} / \mathrm{dL}$, blood urea nitrogen 22 $\mathrm{mg} / \mathrm{dL}$, creatinine $0.4 \mathrm{mg} / \mathrm{dL}$, sodium $129 \mathrm{mEq} / \mathrm{L}$, potassium 6.5 $\mathrm{mEq} / \mathrm{L}$, calcium $10.8 \mathrm{gm} / \mathrm{dL}$ and phosphorus was $6.4 \mathrm{gm} / \mathrm{dL}$.

The patient was treated with appropriate fluid replacement. However, the following day her plasma sodium was 129 $\mathrm{mEq} / \mathrm{L}$, potassium was $8.1 \mathrm{mEq} / \mathrm{L}$ and urine sodium was 31 $\mathrm{mEq} / \mathrm{L}$.

Because of polyuria, her maintenance fluid requirement was calculated taking into consideration the insensible water losses and amount of urine. The patient was monitored and given treatment for hyperpotassemia and sodium deficiency. The etiology of the adrenal insufficiency was investigated. At ultrasonic imaging, the length and thickness of the adrenal cortex was reported as $16.0 \times 4 \mathrm{~mm}$ on the right and $16.5 \times 3.5 \mathrm{~mm}$ on the left. The glands were cribriform in appearance, which is in keeping with findings in congenital adrenal hyperplasia $(\mathrm{CAH})$. With a provisional diagnosis of adrenal insufficiency, the patient was started on hydrocortisone therapy. In blood samples taken before hydrocortisone therapy, plasma adrenocorticotropic hormone level was $5.73 \mathrm{pg} / \mathrm{mL}$, cortisol level $31 \mathrm{ug} / \mathrm{dL}$ and 17-hydroxyprogesterone level was $1.87 \mathrm{ng} / \mathrm{mL}$. These findings led us to reconsider our initial diagnosis of $\mathrm{CAH}$. A tentative diagnosis of hypoaldosteronism was considered. The patient's plasma aldosterone was found to be over $6000 \mathrm{pg} / \mathrm{mL}$ (normal ranges $50-1750 \mathrm{pg} / \mathrm{mL}$ ). Plasma renin activity was $100 \mathrm{ng} / \mathrm{mL}$ (normal ranges 2-5 ng/mL) and saliva sodium level was $152 \mathrm{mEq} / \mathrm{L}$ (normal ranges $33.1 \pm 13.4$ meq/L) (15). These findings were considered to be consistent with a diagnosis of systemic PHA. The patient is still being monitored in our unit and is continuing to be treated with 0.3 $\mathrm{mg} /$ day of fludrocortisone and also receiving treatment for

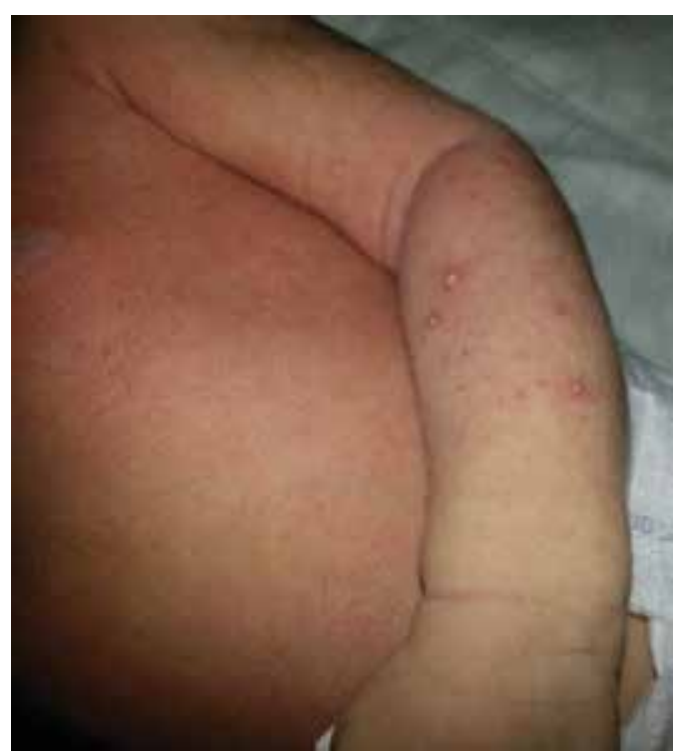

Figure 1. The appearance of the miliaria rubra on the trunk and arm

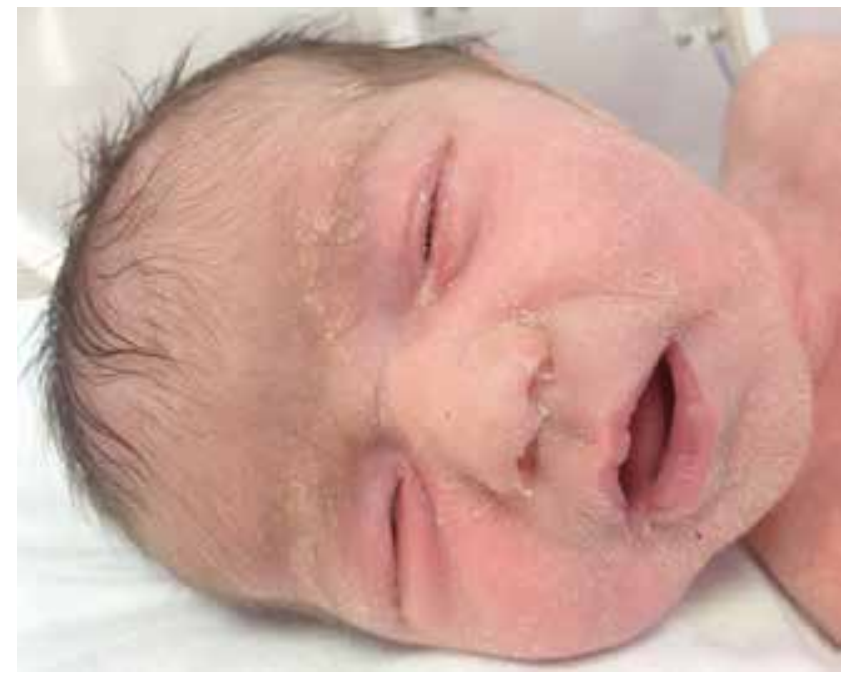

Figure 2. The appearance of salt crystals at the base of the follicles of the face 


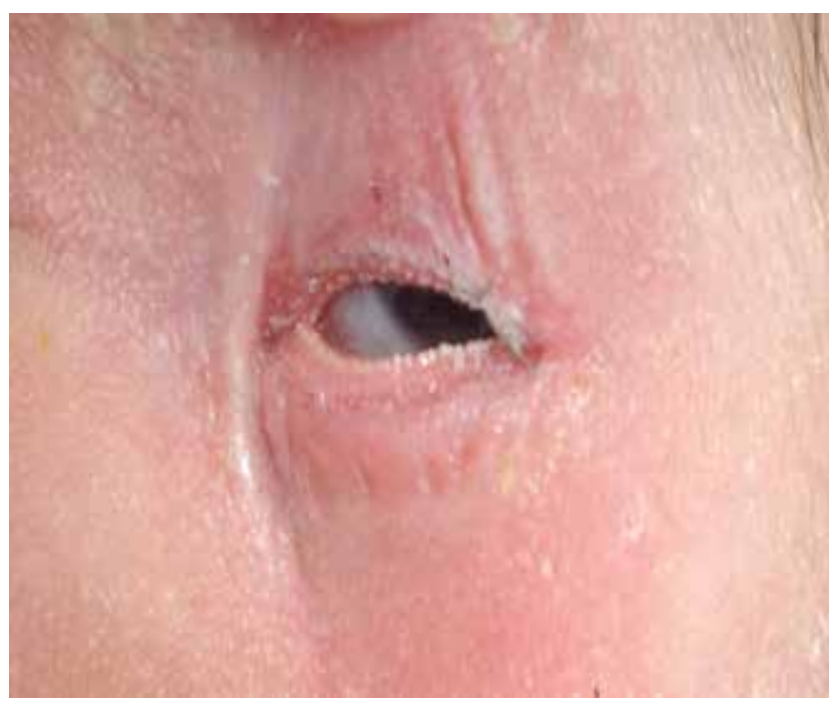

Figure 3. Presence of a white opaque discharge with an appearance of a row of teeth at the bottom of the eyelashes

sodium deficit and hyperpotassemia (glucose buffered insulin, nebulized salbutamol, calcium gluconate and oral kayexalate).

\section{Discussion}

Critical conditions due to salt loss in the neonatal period arise as a result of problems with adrenal hyperplasia which cause salt loss, such as $\mathrm{CAH}$, or of problems with aldosterone secretion (16). Aldosterone deficiency in cases of $\mathrm{CAH}$ is observed in the absence of aldosterone synthase. The presence of aldosterone in high levels despite the crisis of severe salt loss leads to a diagnosis of PHA. The first newborn case was published in 1958 (17).

Two points which cause errors in diagnostic studies related to PHA must be kept in mind. The first of these is that the aldosterone level, which is very high in PHA, may turn out to be low in the first phase as a result of the hook effect caused by the high level of aldosterone (18). The second is that aldosterone levels may not be high in cases of severe sepsis and $\mathrm{CAH}$, as a result of the interference of other hormones and their precursors in serum samples not subjected to extraction and purification (19). Therefore, it is necessary to quantify the 17-hydroxyprogesterone level of the patient, to obtain adrenal ultrasonography results and to do a genetic study before reaching a diagnosis of $\mathrm{PHA}$ and discarding a diagnosis of $\mathrm{CAH}$ or other pathology relating to the adrenal glands. Congenital hydronephrosis and hydroureter cases can also be detected early by renal US. In patients with PHA, it is also essential to quantify the sodium and potassium levels in the serum, urine, sweat glands and saliva for the differential diagnosis of the subtypes of PHA. The fact that the sodium level in saliva was found to be high in our case is a finding which supports a diagnosis of PHA type 1 in autosomal recessive systemic form
$(1,4,5,6)$. In the neonatal period, apart from hyponatremia and hyperpotassemia in the clinical crisis resulting from severe salt loss due to PHA, thrombocytosis is also striking (11). Indeed, our patient had thrombocytosis.

Several diseases may cause a salt-wasting state during infancy, notably severe diarrhea, endocrine abnormalities such as $\mathrm{CAH}$, renal disease and cystic fibrosis. However, none of these conditions are associated with a specific eye abnormality, whereas the detection of dermal and ophthalmic signs in PHA cases may be of great importance for early diagnosis (12). Also in PHA cases, an elevated concentration of salt in the sweat causes cutaneous lesions similar to those which appear in miliaria rubra $(10,11)$. A hypothesis for the cause of skin rash is that secretion of sweat with an elevated sodium chloride concentration directly damages the eccrine ducts. This hypothesis is supported by the fact that this eruption appears during a salt-depletion crisis when the sodium chloride concentration in the sweat is highest. The elevated sodium chloride in the sweat also contributes to formation of inflammatory lesions around the eccrine glands (10). Another typical sign in patients is the presence of ophthalmic problems. The function of the meibomian glands arranged in the ophthalmic tarsal plaque is to produce lipid compounds to prevent drying via evaporation (12). Since the epithelial sodium channels are inactive in PHA cases, formations looking like rows of teeth can appear owing to the accumulation of salt and sebum in the meibomian glands $(12,14)$. Our patient initially presented with skin rash and discharge from the eyes and was followed with a diagnosis of conjunctivitis and infectious dermatitis. It is difficult to differentiate skin lesions in these patients from other nonspecific skin lesions, whereas ocular findings are very typical.

In summary, in this paper, reference was made to the dermal and ophthalmic findings observed in a case of autosomal recessive PHA type 1 hospitalized in the neonatal unit with severe loss of salt and the importance of these findings in providing diagnostic guidance was emphasized.

\section{References}

1. Riepe FG. Clinical and molecular features of type 1 pseudohypoaldosteronism. Horm Res 2009;72:1-9. Epub 2009 Jun 30

2. Tütüncüler F, Günöz H, Bas F, Bundak R, Saka N, Neyzi O. Transient pseudohypoaldosteronism in an infant with urinary tract anomaly. Pediatr Int 2004;46:618-620.

3. Büyükkayhan $D$, Köklü $E$, Görözen $F$, Kurtoğlu $S$, Hatipoğlu $N$, Gündüz Z. An endocrine problem of obstructive uropathy:pseudohypoaldosteronism. Erciyes Medical Journal 2007;29:82-85.

4. Geller DS. Mineralocorticoid resistance. Clin Endocrinol (Oxf) 2005;62:513-520.

5. Hanukoglu A. Type I pseudohypoaldosteronism includes two clinically and genetically distinct entities with either renal or multiple target organ defects. J Clin Endocrinol Metab 1991;73:936-944. 
Korkut $S$ et al.

Ophtalmic Findings in Pseudohypoaldosteronism

6. Root AW. Disorders of aldosterone synthesis, secretion, and cellular function. Curr Opin Pediatr 2014;26:480-486.

7. Güran T, Değirmenci $S$, Bulut IK, Say A, Riepe FG, Güran Ö. Critical points in themanagement of pseudohypoaldosteronism type 1. J Clin Res Pediatr Endocrinol 2011;3:98-100. Epub 2011 Jun 8

8. Rajpoot SK, Maggi C, Bhangoo A. Pseudohypoaldosteronism in a neonate presenting as life-threatening arrhythmia. Endocrinol Diabetes Metab Case Rep 2014;2014:130077. Epub 2014 Mar 1

9. Akçay A, Yavuz T, Semiz S, Bundak R, Demirdöven M. Pseudohypoaldosteronism type 1 and respiratory distress syndrome. J Pediatr Endocrinol Metab 2002;15:1557-1561.

10. Akcakus M, Koklu E, Poyrazoglu H, Kurtoglu S.Newborn with pseudohypoaldosteronism and miliaria rubra. Int J Dermatol 2006;45:1432-1434.

11. Onal H, Adal E, Ersen A, Onal Z, Keskindemirci G. Miliaria rubra and thrombocytosis in pseudohypoaldosteronism: case report. Platelets 2012;23:645-647. Epub 2011 Dec 13

12. Ainsworth JR, Ramsay AS, Galea P, Diaper C. Disordered meibomian gland function in pseudohypoaldosteronism. Arch Ophthalmol 1996;114:1018-1019.
13. Nasir A, Najab IA. Unique eyelid manifestations in type 1 pseudohypoaldosteronism. Arch Dis Child Fetal Neonatal Ed 2012;97:462.

14. Eliwa MS, El-Emmawie AH, Saeed MA. Ocular and skin manifestations in systemic pseudohypoaldosteronism. BMJ Case Rep 2014;2014.

15. Edelman IS, Liebman J. Anatomy of body water and electrolytes. Am J Med 1959;27:256-277.

16. Malikova J, Flück CE. Novel insight into etiology, diagnosis and management of primary adrenal insufficiency. Horm Res Paediatr 2014;82:145-157.

17. Cheek DB, Perry JW. A salt wasting syndrome in infancy. Arch Dis Child 1958;33:252-256.

18. Akin L, Kurtoglu S, Kendirci M, Akin MA, Hartmann MF, Wudy SA. Hook effect: a pitfall leading to misdiagnosis of hypoaldosteronism in an infant with pseudohypoaldosteronism. Horm Res Paediatr 2010;74:7275. Epub 2010 Apr 30

19. Ağladıoğlu SY, Aycan Z, Kendirci HN, Erkek N, Baş VN. Does pseudohypoaldosteronism mask the diagnosis of congenital adrenal hyperplasia ? J Clin Res Pediatr Endocrinol 2011;3:219-221. 